Трубкина Анна Ивановна

ПЕРИОДИЧЕСКИЕ КОНСТРУКЦИИ В ХУДОЖЕСТВЕННОМ ТЕКСТЕ КАК МАРКЕРЫ

\title{
ЯЗЫКОВОГО СОЗНАНИЯ
}

Статья посвящена рассмотрению периодических конструкций как значимого средства репрезентации языкового сознания в художественном тексте. Новизна проведенного исследования состоит в установлении приоритетных функциональных типов текста для реализации периодических конструкций, а также языковых средств, маркирующих языковое сознание автора и персонажа. Диалектика статических и динамических характеристик в их структуре способствует репрезентации различных аспектов языкового сознания и оценки, по преимуществу имплицитной, в авторской или персонажной зонах повествования.

Адрес статьи: www.gramota.net/materials/2/2018/12-3/37.html

\section{Источник}

Филологические науки. Вопросы теории и практики

Тамбов: Грамота, 2018. № 12(90). Ч. 3. С. 603-607. ISSN 1997-2911.

Адрес журнала: www.gramota.net/editions/2.html

Содержание данного номера журнала: www.gramota.net/materials/2/2018/12-3/

\section{() Издательство "Грамота"}

Информация о возможности публикации статей в журнале размещена на Интернет сайте издательства: www.gramota.net Вопросы, связанные с публикациями научных материалов, редакция просит направлять на адрес: phil@gramota.net 
4. Лакофф Дж., Джонсон М. Метафоры, которыми мы живем. М.: Едиториал УРСС, 2004. 256 с.

5. Николаева Е. А. Соотношение стилей американских поэтов начала ХХ века в пространстве лингвистических признаков (на материале лирики Р. Фроста, Э. Робинсона, Э. Лоуэлл и В. Линдзи): автореф. дисс. ... к. филол. н. Смоленск, 2013. 22 c.

6. Тишина А. Е. Основы метафорической системы в индивидуальном стиле А. Ч. Суинберна // Известия Смоленского государственного университета. 2015. № 4 (32). С. 111-118.

7. Тишина А. Е. Особенности внутренней организации метафорической системы А. Ч. Суинберна: динамический аспект // Вестник Челябинского государственного педагогического университета. 2015. № 8. С. 156-162.

8. Тулдава Ю. А. Об измерении связи качественных признаков в лингвистике (1): сопряженность альтернативных признаков // Ученые записки Тартуского университета. Квантитативная лингвистика и автоматический анализ текстов. 1988. Вып. 827. С. 146-162.

9. Swinburne A. C. The Poems of Algernon Charles Swinburne: in 6 volumes. L.: Chatto \& Windus, 1911. Vol. 3. 364 p.

10. Swinburne A. C. The Poems of Algernon Charles Swinburne: in 6 volumes. L.: Chatto \& Windus, 1911. Vol. 5. 424 p.

11. Swinburne A. C. The Poems of Algernon Charles Swinburne: in 6 volumes. N. Y. - L.: Harper and Brothers Publishers, 1911. Vol. 6. 448 p.

\title{
FIGURATIVE SYSTEM'S FEATURES IN A. C. SWINBURNE'S LATE LYRICS: COMBINATORICS OF METAPHORIC MODEL'S CONCEPTUAL FEATURES
}

\author{
Tishina Anna Evgen'evna, Ph. D. in Philology \\ Smolensk State University \\ anna-maksimova-1990@yandex.ru
}

The article presents the results of using the correlation analysis method in the study of A. C. Swinburne's figurative system in his late lyrics. The calculation of the Cole correlation coefficient in the metaphoric models of this period makes it possible to identify the cases of the positive and negative determination of conceptual features, to measure the strength of the registered interdependdencies. On the basis of the obtained data, conclusions are made about the specific mechanisms of the metaphoric system functioning at the final stage of the author's literary path, the directions of its evolution and the individual characteristics of the poet's style as a whole.

Key words and phrases: individual style; quantitative analysis; correlation analysis; Cole coefficient; metaphor; A. C. Swinburne.

УДК 81

https://doi.org/10.30853/filnauki.2018-12-3.37

Статья посвящена рассмотрению периодчческих конструкций как значимого средства репрезентации языкового сознания в художественном тексте. Новизна проведенного исследования состоит в установлении приоритетных функциональных типов текста для реализации периодических конструкций, а также языковых средств, маркирующих языковое сознание автора и персонажа. Диалектика статических и динамических характеристик в их структуре способствует репрезентации различных аспектов языкового сознания и оценки, по преимуществу имплищитной, в авторской или персонажной зонах повествования.

Ключевые слова и фразы: художественный текст; языковое сознание; периодическая конструкция; эмотивность; риторические средства экспрессивности.

Трубкина Анна Ивановна, к. филол. н.

Южный федеральный университет, г. Ростов-на-Дону

aitrubkina@sfedu.ru

\section{ПЕРИОДИЧЕСКИЕ КОНСТРУКЦИИ В ХУДОЖЕСТВЕННОМ ТЕКСТЕ КАК МАРКЕРЫ ЯЗЫКОВОГО СОЗНАНИЯ}

Выступая не только средством общения, но и способом мышления, язык является основой познания мира, что определяет значимое место языкового сознания в лингвокогнитивной деятельности личности. Содержательная сторона языка закономерно связывается со структурами психики человека, которые, в свою очередь, отражают в его сознании различные связи объектов внешнего и внутреннего мира. Именно поэтому язык неправомерно рассматривать вне связей с практикой освоения мира личностью, вне связей с проявлением его психической деятельности. Обращение современной науки о языке к изучению языкового сознания обусловлено антропоцентрическим подходом, а языковое сознание рассматривается и как когнитивный, и как психолингвистический феномен, объективируемый в процессе коммуникации и взаимодействия людей. Языковое сознание может быть изучено как продукт психической и когнитивной деятельности, эксплицированный в артефактах, которые отчуждены от субъекта сознания. Таким образом, необходимость изучения языкового сознания с применением интегрированного подхода очевидна: такой ракурс исследования позволяет рассмотреть языковое сознание не только с позиций его функционирования в речемыслительной деятельности человека, но и специфики его отражения в результатах такой деятельности, в том числе и в художественных текстах. 
Целью статьи является выявление и параметризация свойств периодической конструкции как одного из значимых показателей языкового сознания продуцента художественного текста. Задачи определяются указанной целью: необходимо обосновать лингвокогнитивный статус периодической конструкции и на этой основе уточнить семантику и прагматику периода, обусловленные определенным видом модальности и оценки, а также регистрами субъектно-речевых планов художественного текста (принадлежностью к авторской и/или персонажной зоне повествования).

Актуальность исследования определяется интересом лингвистов к манифестированию когнитивных структур в языке и тексте, в том числе в художественном, а также назревшей необходимостью описания роли периодических конструкций в этом процессе.

Новизна исследования состоит в изучении периодических конструкций как маркеров языкового сознания субъекта речи в художественном тексте на основе выявления коррелятивных связей периодической конструкции с функциональным типом текста, имеющим в качестве смысловой доминанты статику или динамику описываемых явлений. Также при анализе периодических конструкций в художественном тексте привлекаются параметры принадлежности высказывания к авторской или персонажной зоне повествования, имплицитность или эксплицитность оценки.

Под языковым сознанием Е. С. Кубрякова понимает «способ вербализации человеческого социокультурного опыта и его национально-культурного осознания, включающий в себя материальное (языковое знание как материальный субстрат сознания), идеальное (психические состояния, семантика), социокультурный опыт (знания о мире), актуализирующиеся в процессе ментальной деятельности» [1, с. 240]. Как языковое сознание современная лингвистика рассматривает также совокупность образов сознания, которые оформляются посредством ассоциативных полей [7]. Также важной отправной точкой в изучении языкового сознания является понимание объединения в этом феномене двух разных сущностей - сознания как нематериального психического феномена и устной/письменной речи как явления материального, подразумевающего к тому же «физиологический процесс формирования вербальных языковых связей» [9, с. 17].

Закономерным представляется также сближение понятия «языковое сознание» со спецификой речевого поведения личности, в том числе ее коммуникативного репертуара, обусловливаемых «ситуацией общения, языковым и культурным статусом личности, ее психотипом, особенностями мировосприятия» [4, с. 37]. Безусловно, языковое сознание подвергается воздействию и в конечном счете формируется под влиянием национальной культуры ввиду отсутствия четкого разграничения в культурном пространстве элементов языка и элементов культуры. Поэтому рассмотрение манифестирования языкового сознания, возможных форм его репрезентации в художественном тексте является тем направлением, в котором поступательно движется развитие когнитивной лингвистики и лингвокультурологии.

Общеизвестно, что текст объединяет в себе разноуровневые единицы языка с целью осуществления коммуникативной и информативной функций. Язык осуществляет себя в тексте как средство общения, что позволяет выявлять в структуре текста разные характеристики языка (гносеологические, онтологические, коммуникативные). Сознание включает такие компоненты, которые обеспечивают его связь с языком и речью. Языковое сознание привносит в сознание определенные мыслительные модели, отличные от ментальных структур; эти модели позволяют языковой личности воспринимать, перерабатывать, хранить информацию об окружающем мире и о самой себе.

Такие мыслительные модели (схемы) представляют собой совокупность правил, понятий, логических операций, которые необходимы личности в структурировании получаемой информации (отбор, классификация, типологизация информации и пр.). Процесс коммуникации предполагает обмен сообщениями, в ходе которого могут быть выделены главная и второстепенная информация, а также существенные признаки конкретного объекта. Так составляется понятие, которое на основе отбора облигаторных признаков и вычленения релевантных признаков помещается в координаты сознания конкретной личности. Значит, содержание индивидуального сознания составляет обобщенный образ действительности и его отражение в когнитивной деятельности.

В тексте могут быть отражены мыслительные операции, подчиненные, с одной стороны, логическим законам, с другой - характеризующиеся эмотивностью, обеспечиваемой посредством антропоцентричности языка. Художественный текст как объект исследования приобретает в последние два десятилетия особую актуальность: для такого текста характерны максимальная эмотивность и экспрессивность. Эти категории реализуются в художественном тексте различными способами, однако бесспорен приоритет риторических средств. Безусловно, сам выбор того или иного изобразительно-выразительного средства детерминирован его когнитивно-коммуникативным потенциалом, в свою очередь, связанным с эмотивностью, а одним из показателей развитого интеллекта и речевой культуры личности является применение средств экспрессивного синтаксиса.

Синтаксические конструкции, структурированные по модели периода, достаточно частотны в художественных текстах, что обусловлено, прежде всего, возможностью обозначения посредством данного риторического средства признаков ситуации, в том числе и равноправных в своем онтологическом статусе. Кроме того, художественному тексту релевантна реализация периодических конструкций с различными комбинациями паратаксиса и гипотаксиса.

В этой связи необходимо также подчеркнуть, что периодические конструкции отражают специфику языкового сознания автора. Индивидуальные особенности авторского языкового сознания могут быть репрезентированы в отражении процесса формирования мысли как таковой, во внутренней речи персонажей, в манифестировании их типологических личностных характеристик, психологической мотивированности внешних действий и т.п. Другими словами, вся та информация, которая требует детальных авторских комментариев, может быть репрезентирована в форме периодических конструкций с различными типами синтаксической связи. 
Период как маркер языкового сознания в художественном тексте актуализирует убедительную аргументацию, объективирует развитие в таком тексте логического аспекта мышления, а также специфику внутренней речи персонажа либо авторских комментариев. В целом периодические конструкции различных видов способны реализовать когнитивно-прагматический потенциал художественного текста, а также придать необходимую стилистическую окраску конкретному его фрагменту. Мы считаем, что «периодическая конструкция, изучаемая с позиций её семантики, прагматики и функций в художественном тексте, отражает особенности познания внешнего и внутреннего мира, эксплицируя с помощью разноуровневых языковых и дискурсивных средств когнитивно-коммуникативные стратегии продуцента художественного текста, репрезентируя процесс вербализации мысли и целенаправленно воздействуя на его реципиента» [8, с. 5].

Довольно большая протяженность периода, обеспечивающая его стилистическую выделенность на нейтральном текстовом фоне, а также различные объекты внутреннего и внешнего миров, помещенные в один микроконтекст, позволяют судить о высокой степени экспрессивности периодических конструкций. Кроме того, на наш взгляд, целесообразно изучать периодические конструкции не только с позиций их структуры и семантики, но и в аспекте их реализации в авторской либо персонажной зоне повествования, а также с учетом функционального типа текста (описание, повествование, рассуждение).

Так, в следующем примере периодическая конструкция отражает мыслительный процесс персонажа, манифестируя маркеры его языкового сознания: «Пусть бы она стала толще в три раза, пусть бы у нее было пять тромбофлебитов и десять гипертоний, пусть бы у нее были все хворобы мира, - все равно это никакая цена за то, что у нее есть такой сын...» [10]. Периодическая конструкция представляет в приведенном примере функциональный тип текста рассуждение, что обусловлено применением такого типизированного текста, как коммуникативная тактика, для репрезентации отношения героини к происходящему. Сама принадлежность фрагмента к рассуждению объективирована частицей пусть, вводящей условное значение в контекст, а также манифестирование периодической конструкции в персонажной зоне повествования художественного текста. Высокая степень экспрессии, представленная в данном примере, подтверждается гиперболизацией (пять тромбофлебитов, десять гипертоний, толще в три раза), а также употреблением разговорной лексики (хворобы) и лексических сочетаний, характерных для разговорного стиля (никакая цена). Экспликация оценки в приведенном примере позволяет читателю сделать вывод о нежном и трепетном отношении матери к сыну, о ее жертвенности, что, несомненно, оказывает влияние и на сам процесс речемыслительной деятельности персонажа.

Эксплицитная оценка во взаимодействии с функциональным типом текста повествование способствует репрезентации отношения персонажа к происходящему в художественном тексте, одновременно вводит в ход повествования показатели внутреннего мира героя: «А я, вместо того чтобы бежать за ней следом, чтобы хватать ее за руки, целовать ей пальцы, рыдать в ее плечо, в общем, спасать эту мерзкую ситуацию, сижу и натянуто улыбаюсь» [2]. В приведенном примере функциональный тип текста повествование маркирован показателями динамики внешних действий - глаголами бежать, хватать, иеловать, pыдать, сnасать. На наш взгляд, интересно помещение в этот контекст и статических маркеров (сижу, ульљбаюсь), которые определяют не только персонажную эксплицированную оценку, но и оценку происходящего самим читателем.

Разумеется, эксплицитная оценка может быть присуща периодической конструкции и при условии ее реализации в авторской зоне повествования: «Увитые остролиственным плющом каменные стены античной виллы Руфоло, ее мраморные аркады, издали - словно вывязанные тонким крючком; сабельный блеск пальм, черные конусы кипарисов на темно-голубом фоне неба, мощь гигантских пиний, разметавших свои жесткие кроны над праздничной россыпью мандариновых, гранатовых и лимонных плодов на хрупких деревцах, и повсюду с этой немыслимой высоты окрест - слепящая холодная синева Средиземного моря с малахитовыми прожилками глубин - роскошь, избыточная для бедного, давненько лишенного рая человеческого воображения» [6]. В приведенном примере описание в первой части периодической конструкции становится основой введения во второй ее части элементов другого функционального типа текста - рассуждения, при этом значимым признаком функционирования именно этого типа текста является эксплицитно представленная авторская оценка в высказывании «роскошь, избыточная для бедного, давненько лишенного рая человеческого воображения». На наш взгляд, именно этот аспект анализируемого контекста позволяет утверждать, что периодическая конструкция маркирует авторское языковое сознание.

Безусловно, периодические конструкции в художественном тексте способны усилить его полифоничность, что проявляется на уровне совмещения авторской и персонажной зон повествования. Так, периодическая конструкция может быть реализована и в координатах рассуждения как функционального типа текста, например: «Какие бы тренинги вы ни проводили, какие бы рекламные бюджеты вы ни предлагали (безусловно, речь не идет о гигантах типа “Бакарди-Мартини” или “Филипп Моррис”), ничто не заставит его свернуть с пути валовых продаж в сторону наибольшего акцента на вашей марке» [2]. Обращает на себя внимание контаминирование авторской и персонажной зон повествования, которое в наибольшей степени актуализировано в распознаваемой адресатом имплицитной оценке. На наш взгляд, адекватному декодированию смыслов художественного текста способствует в данном случае вставная конструкция «безусловно, речь не идет о гигантах типа "Бакарди-Мартини” или “Филипп Моррис”». Несомненно, периодической конструкции в данном примере присуща текстообразующая функция, а сам период эксплицирует ход мыслительного процесса персонажа.

В следующем примере также встречаем контаминирование авторской и персонажной зон повествования в репрезентации имплицитной оценки: «Главной проблемой Львова было одиночество, которое заставляло его съеживаться в преддверии выходных, когда нечем заняться, некуда пойти, не с кем поговорить, и единственное, чего он ждал, - это уложить спать детей, обсудить с женой их же, детей, новости, вскользь 
коснуться основных событий своей рабочей недели (которые на девяносто пять процентов соответствовали событиям месячной или квартальной давности), безразличным тоном поинтересоваться, что произошло за это время в жизни жены, и, не дожидаясь ответа, откинуть крышку ноутбука и нырнуть в сеть...» [3]. Авторская позиция заявлена в следующем фрагменте: «...главной проблемой Львова было одиночество, которое заставляло его съеживаться в преддверии выходных». Персонажная зона подключается к авторской, начиная со слов когда нечем заняться, некуда пойти и т.п. Текст-повествование, обнаруживая динамику внешних событий, тем не менее не релевантен здесь открытой оценочности прежде всего потому, что такую оценку собственной жизни сам персонаж скрывает от себя, а также потому, что основной задачей автора становится демонстрация речемыслительной деятельности героя.

В дополнение к указанным особенностям, целью периодической конструкции может стать и характеристика персонажей, их внутреннего мира в столкновении с миром внешним, с теми обстоятельствами, которые оказывают влияние на их жизнь и судьбу, например: «Они припомнили мою привычку загибать страницы книг (а ведь книги читаю не я один), то, что я не сдал свои носовые платки в фонд общего пользования (хотя нос растет не у меня одного), что сижу в ванне дольше положенного (двадцать восемь минут вместо двадцати), толкаюсь колесами при езде (а ведь колеса надо беречь!), и наконец добрались до главного - до того, что я курю, если, конечно, можно назвать курящим человека, выкуривающего в течение трех дней одну сигарету» [5]; «Постоянные лучи софитов отучили их глаза воспринимать дневной свет, лампы солярия сделали невозможным нахождение на дневном солнце, тонны парфюмерии и косметики вкупе с наркотиками и диетами постепенно иссушали их тела, а актуальные журналы и развлекательное телевидение сделали то же самое с их мозгом» [2]. В приведенных примерах представлена имплицитная оценка в рамках функционального типа текста рассуждение как повествования от первого лица с узнаваемыми маркерами персонажной зоны - вставными конструкциями, маркирующими мыслительный процесс ( $а$ ведь книги читаю не я один, хотя нос растет не у меня одного), и эксплицитная оценка, направленная на внешний мир (двадцать восемь минут вместо двадцати, а ведь колеса надо беречь!).

Одной из наиболее значимых функций периодической конструкции является также маркирование не только мыслительного процесса, но и эмоционального состояния персонажа: «И мы оба смеемся довольно продолжительно, и мне становится очень весело, и уходит недосып, и кажется, что я вовсе не уезжал из Москвы» [Там же]. В приведенном примере отметим особо контаминирование повествования и описания, что позволяет адресату декодировать эмоциональность персонажа в конкретной сюжетной ситуации, а также динамику развития эмоциональных состояний при имплицировании оценки.

В следующем примере также значима имплицитная персонажная оценка в тексте-повествовании, характеризующем состояние внутреннего мира героя: «Он рано понял, что его не любят, его отличали от других детей, чаще других наказывали и приписывали чужие проступки, он не понимал почему, но не удивлялся и не обижался; он никогда ничему не удивлялся, никогда не ждал от взрослых ничего хорошего; он решил, что взрослые несправедливы, и смирился с этим, научившись делить их на мужчин и женщин, отметил, что женщины относятся к нему хуже, чем мужчины, но и этому факту не стал искать объяснений, а просто принял к сведению, как принимал к сведению все окружавшее его» [5].

Тенденция к более точному и корректному транслированию мыслей в коммуникативном процессе, свойственная системе языка, отражена в самой структуре периодических конструкций и их семантике. С помощью этого важного риторического средства в языке формируются новые формы и связи понятий и объектов экстралингвистической действительности.

Маркирование языкового сознания в художественном тексте семантико-прагматическими средствами как объект исследования диктует рассмотрение периодических конструкций в плане их реализации в функциональном типе текста, в конкретной зоне повествования (авторской либо персонажной), соотносящей ее с имплицитной либо эксплицитной оценкой, которая, в свою очередь, выражена в конкретном отрезке текста. Указанные аспекты позволяют выявить и непротиворечиво описать функции периодических конструкций в плане отражения когнитивной деятельности продуцента художественного текста.

Проведенный анализ позволил сделать выводы об объективации конкретных идей в художественном тексте, в том числе и посредством периодических конструкций. Именно таким путем автору удается акцентировать внимание читателя на конкретных сегментах текста, устанавливая связи между его частями. Основу периодических конструкций составляет повторяемость синтаксических компонентов, которая способствует относительному замедлению действия в художественном тексте и обусловливает предпочтительный выбор описания и рассуждения как ведущих функциональных типов текста с применением периодических конструкций. Повествование в бо́льшей степени ориентируется на динамику события в его репрезентации в художественном тексте, поэтому периодическая конструкция призвана в повествовании привлечь внимание адресата к ключевым событиям либо отразить монотонность и однообразие действия. Диалектика статики и динамики в структуре основных функциональных типов текста позволяет автору варьировать представление посредством периодической конструкции различных аспектов языкового сознания и оценки в авторской или персонажной зонах повествования. К маркерам языкового сознания, усиливающим субъективацию художественного текста, в структуре периодических конструкций на основе проведенного анализа относим следующие: лексика и лексические сочетания, свойственные разговорному стилю, глаголы в различных видовременных формах, вставные конструкции, гиперболизация, повествование от первого лица.

Комплексный анализ периодических конструкций в художественном тексте позволяет также судить о приоритетности имплицитной оценки и эстетической информации в целом, а также о частотном контаминировании авторской и персонажной зон повествования в координатах периодических конструкций. 
Список источников

1. Кубрякова Е. С., Демьянков В. З., Панкрац Ю. Г., Лузина Л. Г. Краткий словарь когнитивных терминов / под общ. ред. Е. С. Кубряковой. М.: Филологический факультет МГУ им. М. В. Ломоносова, 1997. 245 с.

2. Минаев С. Духless. Повесть о ненастоящем человеке [Электронный pecypc]. URL: http://litresp.ru/chitat/ru/M/minaevsergej/duhless-povestj-o-nenastoyaschem-cheloveke\#sec_1 (дата обращения: 09.11.2018).

3. Минаев С. Р.А.Б. [Электронный ресурc]. URL: https://knigogid.ru/books/413929-rab/toread (дата обращения: 09.11.2018).

4. Никитина С. Е. Языковое сознание и самосознание личности в народной культуре // Язык и личность: сборник статей / отв. ред. Д. Н. Шмелев. М.: Наука, 1989. С. 34-41.

5. Петросян М. Дом, в котором... [Электронный ресурc]. URL: https://www.e-reading.club/book.php?book=1015368 (дата обращения: 09.11.2018).

6. Рубина Д. Холодная весна в Провансе [Электронный ресурс]: сб. рассказов. URL: http://knijky.ru/books/holodnayavesna-v-provanse (дата обращения: 09.11.2018).

7. Тарасов Е. Ф. Актуальные проблемы анализа языкового сознания // Языковое сознание и образ мира: сборник научных статей / отв. ред. Н. В. Уфимцева. М.: Институт языкознания РАН, 2000. С. 19-24.

8. Трубкина А. И. Система периодических конструкций в художественном тексте: семантика, прагматика, функции: дисс. ... к. филол. н. Ростов-на-Дону, 2014. 176 с.

9. Ушакова Т. Н. Языковое сознание и принципы его исследования // Языковое сознание и образ мира: сборник научных статей / отв. ред. Н. В. Уфимцева. М.: Институт языкознания РАН, 2000. С. 13-19.

10. Щербакова Г. В. Вам и не снилось [Электронный ресурc]. URL: https://bookriver.org/read.php?b=6872\&p=1 (дата обращения: 09.11.2018).

\title{
PERIODIC CONSTRUCTIONS IN FICTION TEXT AS MARKERS OF LINGUISTIC CONSCIOUSNESS
}

\author{
Trubkina Anna Ivanovna, Ph. D. in Philology \\ Southern Federal University, Rostov-on-Don \\ aitrubkina@sfedu.ru
}

\begin{abstract}
The article is devoted to the consideration of periodic constructions as a significant means of representing linguistic consciousness in fiction text. The novelty of the study is in determining the priority functional types of text for the implementation of periodic constructions, as well as the language means marking the linguistic consciousness of the author and the character. The dialectic of static and dynamic characteristics in their structure contributes to the representation of various aspects of linguistic consciousness and assessment, mainly implicit, in the author's or the character's zone of narration.
\end{abstract}

Key words and phrases: fiction text; linguistic consciousness; periodic construction; emotiveness; rhetorical means of expressiveness.

УДК 811.11

https://doi.org/10.30853/filnauki.2018-12-3.38

Дата поступления рукописи: 10.09.2018

Слух играет при восприятии человеком окружающей действительности весьма важную роль. Статья помогает получить более полное представление о семантике немецких глаголов слуха, так как в существующчих на сегодняшний день исследованиях и лексикографических источниках описаны не все немецкие глаголь слуха, а лишь их небольшая часть. Предпринятое исследование немеиких аудиальных глаголов позволило выявить большое количество синонимов в составе рассматриваемых лексических единиц. Значения глаголов изучались при помощи компонентного анализа. В ходе исследования кроме семного состава значений удалось выявить ряд дополнительных признаков.

Ключевые слова и фpaзы: лингвистика; немецкие глаголы слуха; лексическая семантика; семы; синонимический ряд.

Хантимиров Спартак Мубаракшевич, к. филол. н., доцент Башкирский государственный педагогический университет имени М. Акмулль, г. Уфа ya.spartakkhan@yandex.ru

\section{СЕМАНТИКА НЕМЕЦКИХ ГЛАГОЛОВ СЛУХА}

Каналы восприятия окружающего нас мира очень многообразны: зрительный, слуховой (аудиальный), вкусовой, обонятельный и осязательный. Наиболее важным, естественно, является зрительный канал. Из оставшихся четырех каналов восприятия особенно нагруженным выступает аудиальное восприятие. Это во многом объясняется еще и тем, что именно слуховое восприятие человеком окружающего его пространства выступает в большинстве случаев незаменимым «партнером» зрительного восприятия.

В немецком языке концепт «слушать/слышать» находит свое выражение в большом корпусе лексических единиц, представляющих различные части речи, в т.ч. глаголы. В рамках германистики исследованием семантики глаголов слуха занимались Маурице Флиген [13], О. Н. Григорьева [11]. Проблему синонимии рассматривали такие лингвисты, как Пауль Гребе [8], К. Агрикола [5; 6], Е. Агрикола [6], Эрих Булитта и Хильдегарт Булитта [7], И. В. Рахманов, Н. М. Минина, Д. Г. Мальцева, Л. И. Рахманова [2]. Актуальность данного 